Article

\title{
Surface Water Quality Evaluation Based on a Game Theory-Based Cloud Model
}

\author{
Bing Yang ${ }^{1}(\mathbb{D})$, Chengguang Lai ${ }^{2}$, Xiaohong Chen ${ }^{1,3, *(D)}$, Xiaoqing $\mathrm{Wu}^{4}$ and Yanhu He ${ }^{1,3}$ \\ 1 Center for Water Resource and Environment, Sun Yat-Sen University, Guangzhou 510275, China; \\ yangb56@mail2.sysu.edu.cn (B.Y.); heyanhu3@mail.sysu.edu.cn (Y.H.) \\ 2 School of Civil Engineering and Transportation, South China University of Technology, Guangzhou 510641, \\ China; laichengguang@foxmail.com \\ 3 Guangdong Engineering Technology Research Center of Water Security Regulation and Control for \\ Southern China, Guangzhou 510640, China \\ 4 South China Institute of Environment Sciences, Ministry of Environment Protection of PRC, \\ Guangzhou 510535, China; wxqingAnn@163.com \\ * Correspondence: eescxh@mail.sysu.edu.cn
}

Received: 27 March 2018; Accepted: 18 April 2018; Published: 20 April 2018

\begin{abstract}
Water quality evaluation is an essential measure to analyze water quality. However, excessive randomness and fuzziness affect the process of evaluation, thus reducing the accuracy of evaluation. Therefore, this study proposed a cloud model for evaluating the water quality to alleviate this problem. Analytic hierarchy process and entropy theory were used to calculate the subjective weight and objective weight, respectively, and then they were coupled as a combination weight (CW) via game theory. The proposed game theory-based cloud model (GCM) was then applied to the Qixinggang section of the Beijiang River. The results show that the CW ranks fecal coliform as the most important factor, followed by total nitrogen and total phosphorus, while biochemical oxygen demand and fluoride were considered least important. There were 19 months (31.67\%) at grade I, 39 months $(65.00 \%)$ at grade II, and one month at grade IV and grade V during 2010-2014. A total of 52 months (86.6\%) of GCM were identical to the comprehensive evaluation result (CER). The obtained water quality grades of GCM are close to the grades of the analytic hierarchy process weight $(\mathrm{AHPW})$ due to the weight coefficient of AHPW set to 0.7487. Generally, one or two grade gaps exist among the results of the three groups of weights, suggesting that the index weight is not particularly sensitive to the cloud model. The evaluated accuracy of water quality can be improved by modifying the quantitative boundaries. This study could provide a reference for water quality evaluation, prevention, and improvement of water quality assessment and other applications.
\end{abstract}

Keywords: cloud model; game theory; water quality evaluation; randomness; fuzziness

\section{Introduction}

With the rapid development of the economy and the continued growth of the global population, humans are currently exploring and utilizing limited water resources at an unprecedented rate and scale [1-3]. However, this accelerated human activity has had a negative effect on the water environment in recent decades, contributing to pollution of rivers, estuaries and oceans, especially in developing countries [4,5]. Undoubtedly, water quality degradation has been acknowledged as one of the most severe environmental issues worldwide since it disrupts the ecological balance of water bodies and threatens regional environmental security [6-8]. Therefore, this issue attracts significant attention across the world.

Water quality evaluation is one of the basic methods to analyze water quality condition and has been considered as an essential measure and has since diversified. Nevertheless, two types of 
uncertainty should still be considered in water quality evaluation: the first is randomness, which is often exhibited in the monitoring and analysis of data related to water quality; the second is fuzziness, which often reflects the classification standard, evaluation class, and degree of pollution [9]. Most contemporary water quality evaluation methods or models, such as the single factor evaluation method, the Nemerow pollution index, the fuzzy comprehensive evaluation, and the artificial neural network method, can be divided into three types according to these two forms of uncertainties: the first type of model is mainly based on various statistical and stochastic techniques for randomness [10-12]; the second type of model is mainly based on fuzzy membership function, fuzzy logic, and fuzzy set theory for fuzziness $[13,14]$; and the last type of model is based on machine learning and artificial intelligence for unknown patterns that hardly capture key information during the assessment process [15-17]. The three types of methods or models provide superior tools to evaluate the water quality and greatly contribute to regional water quality protection.

As mentioned before, since randomness and fuzziness are widely considered in water quality evaluation, it would be better if a method or model existed that could reduce both randomness and fuzziness. Fortunately, a new model, i.e., the cloud model was proposed with the purpose of reducing randomness and fuzziness in system evaluation [18]. This model can quantify both randomness and fuzziness via three fixed parameters and presents more advantages than a single randomness or fuzziness model. Due to these advantages, Wang et al. [19] first applied this model to the field of water quality evaluation and achieved satisfactory results. Nevertheless, water quality evaluation is a process of multi-criteria decision-making and therefore a key issue remains in the cloud model, i.e., how to determine appropriate index weights. Reasonable evaluation results mainly depend on index weight so that the determination of an appropriate index weight becomes a key step in the evaluation process [20,21].

Currently, subjective weight and objective weight are two common weights while both have their limitations. The former is strongly affected by expert knowledge as well as many biases, resulting in high subjectivity [22], while the later does not consider differences among indices, and it ignores practical situations [23]. Therefore, a combination weight, with the advantages of both subjective weight and objective weight, should be used to solve the aforementioned problems. Game theory is the mathematical modeling of strategic interaction among rational and irrational agents that specializes in solving conflicts among two or more participants [24,25]. In game theory, each participant's objective is to maximize the expected value of his own payoff, and the decision made by all participants is rational for each individual participant $[26,27]$. Therefore, all participants reach an independent but collective decision that maximizes all of the participants' expected utility payoffs, suggesting that the decision includes either a consensus or a compromise. This factor is known as the Nash Equilibrium [28]. Subjective weight and objective weight, analogously, can be regarded as two participants of the game, and the combination weight is the result of the 'weight' game. The most satisfied combination weight is considered that have reached the Nash Equilibrium, according to game theory. However, little attention has been paid to the concept of game theory for determining a comprehensive weight in water quality evaluation, let alone applying the combination weight to the cloud model of water quality evaluation.

Therefore, the main objectives of this study are (1) to calculate a combination weight based on game theory integrating subjective weight and objective weight; (2) to construct an evaluation system of the cloud model; and (3) to analyze water quality grade in the study areas. This study aims to provide scientific and practical measures for water quality evaluation, prevention, and improvement of water quality assessment and other applications in the study areas.

\section{Study Site and Data}

The study focuses on the Beijiang River, which is the second largest tributary of the Pearl River [29]. The Beijiang River originates from Xinfeng County in Jiangxi province, and flows through Shaoguan City, Qingyuan City, and Foshan City of Guangdong province. The total length of the Beijiang River 
is $573 \mathrm{~km}$, with a catchment area of $52,068 \mathrm{~km}^{2}$, accounting for $10.3 \%$ of the total area of the Pearl River basin.

The water quality data used in this study were collected from the Qixinggang section (QXG; $111^{\circ} 04^{\prime} 03^{\prime \prime} \mathrm{E}, 23^{\circ} 41^{\prime} 00^{\prime \prime} \mathrm{N}$ ), i.e., the national control section of surface water in the Beijiang River (Figure 1). The QXG is located in the center of Qingyuan city and it is a key monitoring point of the entire Beijiang River. The employed values in this study consisted of nine evaluation indices, including dissolved oxygen (DO), permanganate index (PI), chemical oxygen demand (COD), biochemical oxygen demand (BOD), ammonium nitrogen $\left(\mathrm{NH}_{4}{ }^{+}-\mathrm{N}\right)$, total phosphorus (TP), total nitrogen (TN), fluoride $(\mathrm{F})$, and fecal coliform $(\mathrm{Fc})$, and these data were monitored monthly from January 2010 to December 2014. The quality of these data satisfied the national standards and professional standards. Additionally, we used the z-score method [30] to standardize these indices, thus avoiding inconsistency induced by measurement and calculation.

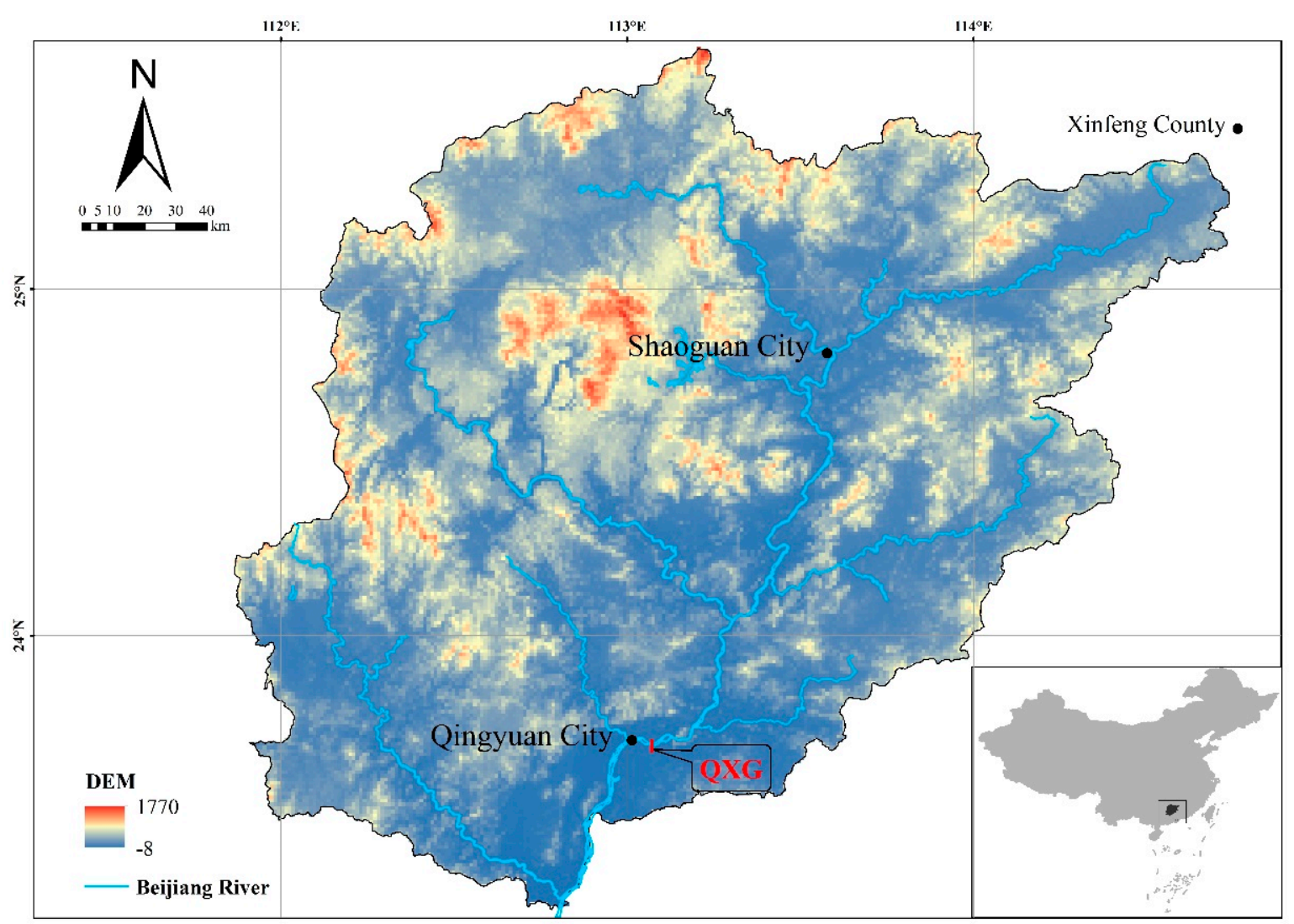

Figure 1. Location map of the monitoring section in the study area.

\section{Methodology}

The framework of water quality cloud model evaluation of the game theory-based cloud model is illustrated in Figure 2. In this study, we first selected suitable water quality indices and transferred these to standardized dimensionless data; we then determined water quality criteria and calculated each index's combination weight according to the game theory concept. The subjective weight and objective weight were combined via the analytic hierarchy process (AHP) and entropy theory, respectively. Here, we determined the cloud model parameters and input the parameters into the normal cloud generator to generate the cloud, and the comprehensive certainty degree was computed using the combination weight. Lastly, the water quality grade was determined according to the rank of the maximum certainty degree of each evaluation index calculated from the cloud model. This research 
divides the water quality into six grades: grades I, II, III, IV, V, and VI. The main implemented software includes R studio and Excel.

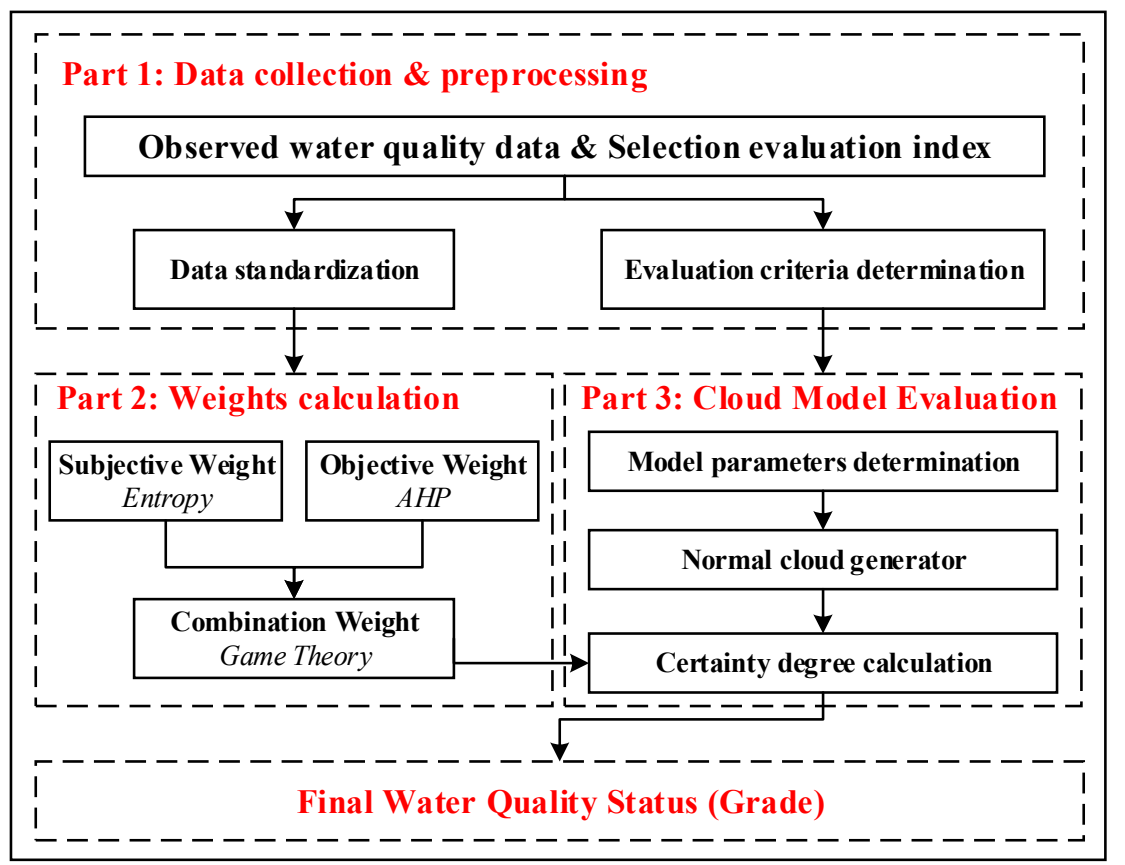

Figure 2. Framework of the cloud model-based water quality evaluation approach.

\subsection{Cloud Model}

\subsubsection{Overview of the Model}

The cloud model, first proposed by Li et al. [18,31], is a type of transformation model that synthetically describes the randomness and fuzziness of concepts and can implement the uncertain transformation between a qualitative concept and its quantitative instantiations.

Given a qualitative concept $T$ defined over a universe of discourse $U=\{u\}$, let $x \in U$ is a random instantiation of the concept $T$ and $\mu_{T}(x) \in[0,1]$ is the certainty degree of $x$ belonging to $T$, which corresponds to a random number with a steady tendency. Then, the distribution of $x$ in the universe $U$ can be defined as a cloud and $x$ can be called a cloud drop. The point here is that the random instantiation is the instantiation in the sense of probability theory. Thus, $\forall x \in U$, the mapping $\mu_{T}(x)$ is a one-to-many mapping in nature, i.e., the certainty degree of $x$ belonging to the concept $T$ is a probability distribution rather than a fixed number.

\subsubsection{Model Parameters}

The cloud model can effectively integrate both randomness and fuzziness of concepts and describe the overall quantitative property of a concept by the four numerical characteristics as follows:

$E_{x}$ (Expectation) represents the mathematical expectation that the cloud drops belong to a concept in the universe. It can be regarded as the most representative and typical sample of the qualitative concept.

$E_{n}$ (Entropy) represents the uncertainty measurement of a qualitative concept. It is determined by both randomness and the fuzziness of the concept. In one aspect, as the measurement of randomness, $E_{n}$ reflects the dispersing extent of the cloud drops and in the other aspect, it is also the measurement of fuzziness, representing the scope of the universe that can be accepted by the concept.

$H_{e}$ (Hyper entropy) represents the uncertain degree of entropy $E_{n}$.

$N$ represents the number of the repeat simulations. Note that in Figure 3, the x-axis represents the values of the water quality index, and the y-axis represents the certainty degree of a water quality grade. 


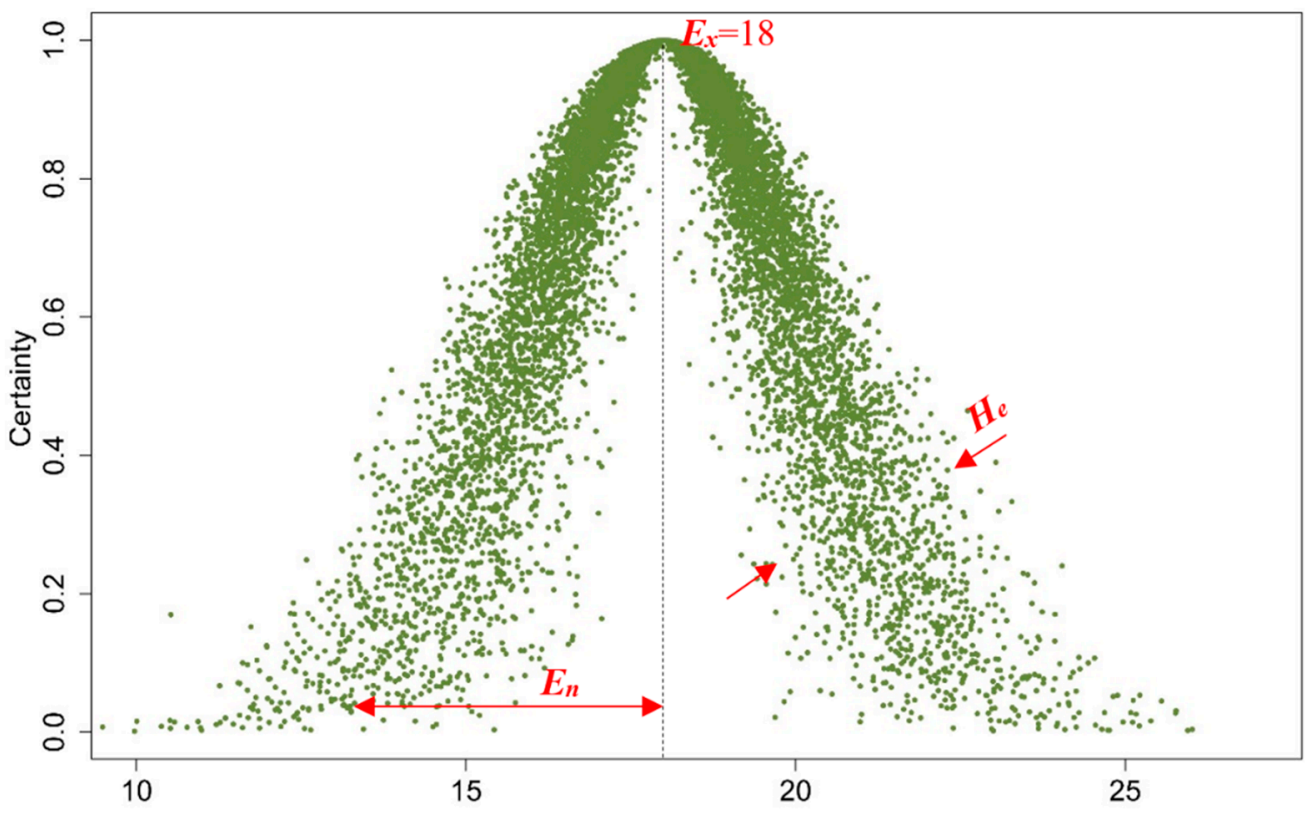

Figure 3. Schematic diagram of the cloud $(N=50,000)$.

For the determination of $\left(E_{x}, E_{n}, H_{e}\right)$, Du et al. [32] suggested Equation (1) for a bilateral boundary of the form $\left(B_{\min }, B_{\max }\right)$ :

$$
\left\{\begin{array}{c}
E_{x}=\left(B_{\min }+B_{\max }\right) / 2 \\
E_{n}=\left(B_{\max }-B_{\min }\right) / 6 \\
H_{e}=k
\end{array}\right.
$$

where $B_{\min }$ and $B_{\max }$ are the respective minimum and maximum values that can be accepted qualitatively; i.e., in water quality evaluation, the minimum and maximum values corresponding to a certain water quality grade in each criterion to obtain the value of $E_{x}$.

Note that $k$ is a constant and can be adjusted according to the practical situation. In the present study, the algorithm of $H_{e}$ was modified as follows: hyper entropy $H_{e}$ is the uncertainty degree of entropy $E_{n}$; however, in Equation (1) $H_{e}$ is assumed as a constant irrelevant to $E_{n}$, and it is assumed that $H_{e}$ can be adjusted by a linear relationship with $E_{n}$ :

$$
H_{e}=k \times E_{n}
$$

In this way, $k$ intuitively controls the 'atomization' degree of the normal cloud model (Figure 3 ) and essentially reflects the variation of cognition of different evaluations. Here, $k$ is assumed to be 0.1 to balance the variation and robustness of the assessment [33].

In this case, combined with standard water quality criteria (Table 1$)$, the three perimeters $\left(E_{x}, E_{n}\right.$, and $H_{e}$ ) of each evaluation index were calculated according to Equations (1) and (2). The modified equations are applicable for fixed intervals, noting that for grade VI of criterion PI, COD, BOD, $\mathrm{NH}_{4}{ }^{+}-\mathrm{N}, \mathrm{P}, \mathrm{N}, \mathrm{F}, \mathrm{Fc}$, and for grade I of criterion DO, $B_{\max }$ is missing. To attain the pseudo boundary, a hypothetical process indicates that $B_{\max }$ is twice as large as $B_{\min }$. For example, for grade II of PI, $B_{\min }=2$, and $B_{\max }=4$ (see Table 1), the corresponding parameters can be obtained as $E_{x}=3$ and $E_{n}=1 / 3$. For grade VI of COD, $B_{\min }=40$, and $B_{\max }=2 \times B_{\min }=80$, the corresponding parameters can be obtained as $E_{x}=60$ and $E_{n}=6.67$. After attaining all quantitative boundaries of the grades of all criteria, all parameters are presented in Table 2. $N$ was set to 2000 in this study to balance accuracy, robustness, and computational expense. 
Table 1. Quantitative boundaries of water quality grades of all criteria [34].

\begin{tabular}{ccccccc}
\hline Evaluation Factor & Grade I & Grade II & Grade III & Grade IV & Grade V & Grade VI \\
\hline $\mathrm{DO}(\mathrm{mg} / \mathrm{L})$ & $\geq 7.5$ & $\geq 6$ & $\geq 5$ & $\geq 3$ & $\geq 2$ & $<2$ \\
$\mathrm{PI}(\mathrm{mg} / \mathrm{L})$ & $\leq 2$ & $\leq 4$ & $\leq 6$ & $\leq 10$ & $\leq 15$ & $>15$ \\
$\mathrm{COD}(\mathrm{mg} / \mathrm{L})$ & $\leq 15$ & $\leq 15$ & $\leq 20$ & $\leq 30$ & $\leq 40$ & $>40$ \\
$\mathrm{BOD}(\mathrm{mg} / \mathrm{L})$ & $\leq 3$ & $\leq 3$ & $\leq 4$ & $\leq 6$ & $\leq 10$ & $>10$ \\
$\mathrm{NH}_{4}^{+}-\mathrm{N}(\mathrm{mg} / \mathrm{L})$ & $\leq 0.15$ & $\leq 0.5$ & $\leq 1$ & $\leq 1.5$ & $\leq 2$ & $>2$ \\
$\mathrm{TP}(\mathrm{mg} / \mathrm{L})$ & $\leq 0.02$ & $\leq 0.1$ & $\leq 0.2$ & $\leq 0.3$ & $\leq 0.4$ & $>0.4$ \\
$\mathrm{TN}(\mathrm{mg} / \mathrm{L})$ & $\leq 0.2$ & $\leq 0.5$ & $\leq 1$ & $\leq 1.5$ & $\leq 2$ & $>2$ \\
F $(\mathrm{mg} / \mathrm{L})$ & $\leq 1$ & $\leq 1$ & $\leq 1$ & $\leq 1.5$ & $\leq 1.5$ & $>1.5$ \\
FC (Number) & $\leq 200$ & $\leq 2000$ & $\leq 10,000$ & $\leq 20,000$ & $\leq 40,000$ & $>40,000$ \\
\hline
\end{tabular}

Table 2. Cloud model parameters of water quality grades of all criteria.

\begin{tabular}{|c|c|c|c|c|c|c|c|c|c|}
\hline \multirow{2}{*}{ Grade } & \multicolumn{3}{|c|}{ DO } & \multicolumn{3}{|c|}{ PI } & \multicolumn{3}{|c|}{ COD } \\
\hline & $E_{x}$ & $E_{n}$ & $H_{e}$ & $E_{x}$ & $E_{n}$ & $H_{e}$ & $E_{x}$ & $E_{n}$ & $H_{e}$ \\
\hline I & 11.25 & 1.25 & 0.13 & 1 & 0.33 & 0.03 & 7.5 & 2.5 & 0.3 \\
\hline II & 6.75 & 0.25 & 0.025 & 3 & 0.33 & 0.03 & 15 & 2.5 & 0.3 \\
\hline III & 5.5 & 0.17 & 0.017 & 5 & 0.33 & 0.03 & 17.5 & 0.83 & 0.1 \\
\hline IV & 4 & 0.33 & 0.033 & 8 & 0.67 & 0.067 & 25 & 1.67 & 0.17 \\
\hline $\mathrm{V}$ & 2.5 & 0.17 & 0.017 & 12.5 & 0.83 & 0.083 & 35 & 1.67 & 0.17 \\
\hline VI & 1 & 0.33 & 0.033 & 22.5 & 2.5 & 0.25 & 60 & 6.67 & 0.7 \\
\hline \multirow{2}{*}{ Grade } & \multicolumn{3}{|c|}{ BOD } & \multicolumn{3}{|c|}{$\mathrm{NH}_{4}{ }^{+}-\mathrm{N}$} & \multicolumn{3}{|c|}{ TP } \\
\hline & $E_{x}$ & $E_{n}$ & $H_{e}$ & $E_{x}$ & $E_{n}$ & $H_{e}$ & $E_{x}$ & $E_{n}$ & $H_{e}$ \\
\hline I & 1.5 & 0.5 & 0.05 & 0.075 & 0.03 & 0.003 & 0.01 & 0.003 & 0.0003 \\
\hline II & 3 & 0.5 & 0.05 & 0.33 & 0.058 & 0.006 & 0.06 & 0.013 & 0.001 \\
\hline III & 3.5 & 0.17 & 0.017 & 0.75 & 0.08 & 0.008 & 0.15 & 0.017 & 0.002 \\
\hline IV & 5 & 0.33 & 0.033 & 1.25 & 0.08 & 0.008 & 0.25 & 0.017 & 0.002 \\
\hline $\mathrm{V}$ & 8 & 0.67 & 0.067 & 1.75 & 0.08 & 0.008 & 0.35 & 0.017 & 0.002 \\
\hline VI & 15 & 1.67 & 0.167 & 3 & 0.33 & 0.033 & 0.6 & 0.067 & 0.007 \\
\hline \multirow{2}{*}{ Grade } & \multicolumn{3}{|c|}{$\mathrm{TN}$} & \multicolumn{3}{|c|}{$\mathbf{F}$} & \multicolumn{3}{|c|}{ Fc } \\
\hline & $E_{x}$ & $E_{n}$ & $H_{e}$ & $E_{x}$ & $E_{n}$ & $H_{e}$ & $E_{x}$ & $E_{n}$ & $H_{e}$ \\
\hline $\mathrm{I}$ & 0.1 & 0.03 & 0.003 & 0.5 & 0.17 & 0.017 & 100 & 33 & 3.3 \\
\hline II & 0.35 & 0.05 & 0.005 & 1 & 0.17 & 0.017 & 1100 & 300 & 30 \\
\hline III & 0.75 & 0.08 & 0.008 & 1 & 0.17 & 0.017 & 6000 & 1333 & 133.3 \\
\hline IV & 1.25 & 0.08 & 0.008 & 1.25 & 0.08 & 0.008 & 15,000 & 1667 & 166.7 \\
\hline $\mathrm{V}$ & 1.75 & 0.08 & 0.008 & 1.5 & 0.08 & 0.008 & 30,000 & 3333 & 333.3 \\
\hline VI & 3 & 0.33 & 0.033 & 2.25 & 0.25 & 0.025 & 60,000 & 6667 & 670 \\
\hline
\end{tabular}

\subsubsection{Formation of the Cloud}

Cloud models are executed by cloud generators. Generally, two types of cloud generators exist: forward and the backward cloud generators. A forward cloud generator is the transformation between the qualitative knowledge and the quantitative representation and is used to generate the cloud drops through these given cloud numerical descriptors and it can be denoted with CG. Given these numerical descriptors of cloud and the specified $x=x_{0}$, the combination to generator the cloud drops drop $(x, \mu(x))$ is called the X-condition cloud, which can be denoted by XCG. The backward generator is a transferring process to derive the qualitative concept, represented by three descriptors from cloud drops and it can be denoted by $\mathrm{CG}^{-1}$. The three cloud generators are shown in Figure 4 . The combination of the two types of generators can be used interchangeably to derive various types of clouds to bridge the gap between qualitative concept and quantitative knowledge. 


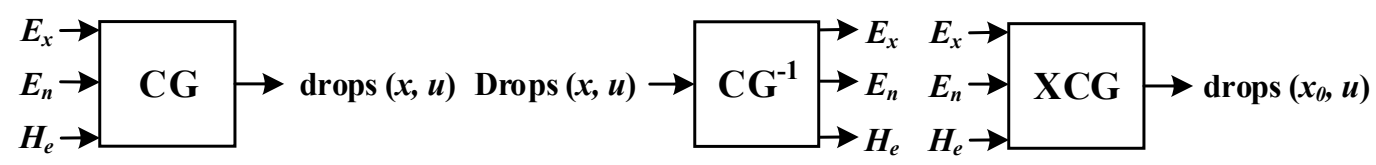

Figure 4. Process of forward cloud generators, backward cloud generators, and X-condition cloud generators.

The normal cloud model has been shown to be universally applicable and has been applied in the field of water science [19]. It is also an important type of cloud model based on normal distribution and Gauss membership function. This type of model is used in this study, and the algorithm steps of the forward normal cloud generator are as follows:

Input: Three parameters $E_{x}, E_{n}, H_{e}$, and the number of cloud drops $N$.

Output: $N$ cloud drops and their certainty degree.

Steps:

(1) Generate a normally distributed random number $E_{n_{i}}^{\prime}$ with expectation $E_{n}$ and variance $H_{e}^{2}$;

(2) Generate a normally distributed random number $x_{i}$ with expectation $E_{x}$ and variance $E_{n_{i}}^{\prime}$;

(3) Calculate $y_{i}=e^{\frac{-\left(x-E_{x}\right)^{2}}{2\left(E n_{i}^{\prime}\right)^{2}}}$, where $x_{i}$ represents a cloud drop in the universe and $y_{i}$ is the certainty degree of $x_{i}$ belongs to the concept $\widetilde{A}$; and

(4) Repeat steps 1-3 until $N$ cloud drops are generated.

\subsection{Combination Weight Based on Game Theory}

Combination weight, integrating subjective weight and objective weight through a certain algorithm is more reasonable for the evaluation process [35]. The game theory calculation steps of the combination weight with two or more participants are as follows:

Step 1 . Because the weight results obtained by different weighting methods can vary widely and even contradict each other, it is necessary to verify the consistency of each weight before combining them. If the weights do not pass the consistency check, then adjustments have to be made to meet the requirements. Since this paper only uses two weight calculation methods, the following distance equation can be used for testing:

$$
d\left(w^{(1)} w^{(2)}\right)=\left[\frac{1}{2} \sum_{i=1}^{m}\left(w_{i}^{(1)}-w_{i}^{(2)}\right)^{2}\right]^{\frac{1}{2}}
$$

where $m$ represents the number of index vectors that are included in each set of weights and $d\left(w^{(1)} w^{(2)}\right)$ represents the degree of consistency between the two groups. The smaller the $d\left(w^{(1)} w^{(2)}\right)$, the higher the consistency. When $d\left(w^{(1)} w^{(2)}\right)$ is below 0.2 , the consistency test is passed, and the next coupling can be carried out after a consistency check.

Step 2. Obtain $n$ weights according to $n$ types of weighting methods, and then construct a basic weight vector set $U=\left\{u_{1}, u_{2}, \cdots, u_{n}\right\}$. A possible weight set is combined by $n$ vectors with the form of arbitrary linear combination as:

$$
U=\sum_{k=1}^{n} \alpha_{k} u_{k}^{T}\left(a_{k}>0\right)
$$

where $u$ represents a possible weight vector in set $U$ and $\alpha_{k}$ represents the weight coefficient.

Step 3. Determine the most satisfied weight vector $u^{*}$ of the possible weight vector sets according to the concept of game theory, suggesting that a compromise is reached among $n$ weights. Such a compromise can be regarded as optimization of the weight coefficient $\alpha_{k}$, which is a linear combination. The optimization aim is to minimize the deviation between $u$ and $u_{k}$ using the following equation: 


$$
\min \left\|\sum_{j=1}^{n} \alpha_{j} \times u_{j}^{T}-u_{i}^{T}\right\|_{2}(i=1,2, \cdots, n)
$$

According to the differentiation property of the matrix, the condition of the optimal first order derivative in Equation (5) is:

$$
\sum_{j=1}^{n} \alpha_{j} \times u_{i} \times u_{j}^{T}=u_{i} \times \cdots u_{i}^{T}(i=1,2, \cdots, n)
$$

The corresponding system of linear equations is:

$$
\left[\begin{array}{cccc}
u_{1} \cdot u_{1}^{T} & u_{1} \cdot u_{2}^{T} & \cdots & u_{1} \cdot u_{n}^{T} \\
u_{2} \cdot u_{1}^{T} & u_{2} \cdot u_{2}^{T} & \cdots & u_{2} \cdot u_{n}^{T} \\
\vdots & \vdots & \vdots & \vdots \\
u_{n} \cdot u_{1}^{T} & u_{n} \cdot u_{2}^{T} & \cdots & u_{n} \cdot u_{n}^{T}
\end{array}\right]\left[\begin{array}{c}
\alpha_{1} \\
\alpha_{2} \\
\vdots \\
\alpha_{n}
\end{array}\right]=\left[\begin{array}{c}
u_{1} \cdot u_{1}^{T} \\
u_{2} \cdot u_{2}^{T} \\
\vdots \\
u_{n} \cdot u_{n}^{T}
\end{array}\right]
$$

Step 4. Calculate the weight coefficient $\left(\alpha_{1}, \alpha_{2}, \cdots, \alpha_{n}\right)$ according to Equation (7), and then normalize it with the following equation:

$$
\alpha_{k}^{*}=\frac{\alpha_{k}}{\sum_{k=1}^{n} \alpha_{k}}
$$

Lastly, the combination weight will be obtained as:

$$
u^{*}=\sum_{k=1}^{n} \alpha_{k}^{*} \cdot u_{k}^{T}
$$

In this case, the subjective weight was calculated via AHP [36-39]. Five experts were invited to participate in the judgment and then, the average of their judgment value was used. The judgment matrix was established with the consistency ratio $(C R=0.0268)$ which meets the condition $C R<0.1$. The consistency ratio must be computed to check for discordances between the pairwise comparisons and the reliability of the obtained weights [40]. Then, the subjective weight based on AHP (AHPW) was finally determined. The objective weight was calculated via information entropy theory (EW) [41-44] using a program written in R language. The subjective weight (AHPW) and objective weight (EW) passed the consistency test of Equation (3), with the $d\left(w^{(1)} w^{(2)}\right)=0.167(<0.2)$.

\section{Results and Discussion}

\subsection{Analysis of Index Weight}

As described above, this study only uses two weight calculation methods to calculate the comprehensive weight, meaning $n=2$ in Equations (4)-(9). At the same time, according to the calculation of Equations (7) and (8), the weight coefficients used to calculate the subjective and objective weights of the comprehensive weights are $\alpha_{1}=0.7487$ and $\alpha_{2}=0.2513$, respectively. The final calculated results of subjective, objective, and comprehensive weights are shown in Table 3 . We can see that the AHPW ranks Fc, TN, and TP as three most important indices among nine factors, while $\mathrm{F}$ is ranked as the least important factor. For the objective weight, the EW regards $\mathrm{NH}_{4}{ }^{+}-\mathrm{N}$ and TP as the most important indexes, and BOD and Fc as the least important indexes. Similar to AHPW, the CW ranks Fc as the most important, followed by TN and TP, while the BOD and F are considered as the least important. Since the intentions are generally affected by experts' various opinions, these subjective interpretations in many cases mainly depend on their experience and level of understanding, which may cause errors or even unreasonable results. The EW is based on the internal law of index data and 
reflects the useful information of the index. However, it does not consider the differences of practical situations of each index, causing dissatisfied results that deviated from the decision makers' subjective cognition. After investigating the actual pollution situation in the study area, it was learned that the monitoring section was located downtown, surrounded by residents' living quarters. There were no large factories and enterprises in the upstream area. Therefore, the major sources of pollution in the study area are domestic sewage and agricultural fertilizers. Although Fc should be larger in our subjective cognition because it is the most intuitive embodiment of organic pollutants, the value of 0.089 in EW appears very far from actual conditions. Therefore, both AHPW and EW have rationality and non-rationality. The AHPW can flexibly reflect the intentions of decision makers but does not consider the data internal law, and EW can show the internal law and useful information but ignores practical situations. Therefore, the combination weight $(\mathrm{CW})$, with the advantages of both subjective weight and objective weight, should be a reasonable method to solve the aforementioned problems.

Table 3. Index weights obtained by the three methods.

\begin{tabular}{cccccccccc}
\hline Index & DO & PI & COD & BOD & $\mathbf{N H}_{4}{ }^{+}-\mathbf{N}$ & TP & TN & F & Fc \\
\hline AHPW & 0.081 & 0.098 & 0.070 & 0.067 & 0.078 & 0.133 & 0.161 & 0.031 & 0.281 \\
EW & 0.116 & 0.100 & 0.089 & 0.078 & 0.159 & 0.140 & 0.108 & 0.121 & 0.089 \\
CW & 0.090 & 0.099 & 0.075 & 0.070 & 0.098 & 0.135 & 0.148 & 0.054 & 0.233 \\
\hline
\end{tabular}

\subsection{Analysis of Water Quality and Comparison with Other Methods}

The water quality was classified by six grades in this study, i.e., lower grade means better water quality. The validity of the proposed game theory-based cloud model (GCM) approach was assessed via comparison with two other methods: the comprehensive evaluation result (CER) and the single factor index method (SFI). In this study, the CERs were officially provided by the local department of environmental protection and these are considered as a reference standard. It is a synthesized result of experts' comprehensive analysis of the water quality results calculated by the pollution index method, single factor evaluation method, fuzzy mathematical evaluation method, gray system evaluation method, and artificial neural network evaluation method. The SFI uses the surface water environmental quality standard [34] corresponding to the worst water quality indicator to determine the final water quality grade [45]. Results of the three methods are shown in Figure 5.

\begin{tabular}{|c|c|c|c|c|c|c|c|c|c|c|c|c|c|}
\hline Methods & Time & Jan. & Feb. & Mar. & Apr. & May & Jun. & Jul. & Aug. & Sep. & Oct. & Nov. & Dec. \\
\hline \multirow{5}{*}{ CER } & 2010 & II & I & I & I & I & I & II & I & II & I & II & I \\
\hline & 2011 & I & I & I & I & II & II & II & II & I & I & II & II \\
\hline & 2012 & $\mathrm{I}$ & $\mathrm{I}$ & II & $\mathrm{I}$ & II & II & $\mathrm{I}$ & II & II & II & II & II \\
\hline & 2013 & $\mathrm{I}$ & $\mathrm{I}$ & $\mathrm{I}$ & II & II & $\mathrm{I}$ & II & $\mathrm{I}$ & II & II & $\mathrm{I}$ & II \\
\hline & 2014 & II & II & II & II & II & II & I & I & I & II & I & I \\
\hline \multirow{5}{*}{ GCM } & 2010 & II & $\mathrm{V}$ & $\mathrm{I}$ & $\mathrm{I}$ & $\mathrm{I}$ & $\mathrm{I}$ & II & $\mathrm{I}$ & II & $\mathrm{I}$ & II & $\mathrm{I}$ \\
\hline & 2011 & II & I & $\mathrm{I}$ & $\mathrm{I}$ & II & II & II & II & $\mathrm{I}$ & $\mathrm{I}$ & II & II \\
\hline & 2012 & $\mathrm{I}$ & II & II & I & II & II & II & II & II & II & II & II \\
\hline & 2013 & $\mathrm{I}$ & $\mathrm{I}$ & $\mathrm{I}$ & II & II & II & II & $\mathrm{I}$ & II & II & $\mathrm{I}$ & II \\
\hline & 2014 & II & II & II & II & II & II & $\mathrm{I}$ & $\mathrm{V}$ & IV & II & I & II \\
\hline \multirow{5}{*}{ SFI } & 2010 & III & $\mathrm{V}$ & II & II & $\mathrm{I}$ & $\mathrm{I}$ & II & $\mathrm{I}$ & II & $\mathrm{I}$ & II & $\mathrm{I}$ \\
\hline & 2011 & III & I & $\mathrm{I}$ & IV & II & III & II & II & $\mathrm{I}$ & $\mathrm{I}$ & III & II \\
\hline & 2012 & II & I & II & I & II & II & III & II & II & II & II & IV \\
\hline & 2013 & $\mathrm{I}$ & III & I & III & II & III & II & IV & II & II & III & II \\
\hline & 2014 & II & III & III & III & II & III & IV & $\mathrm{V}$ & $\bar{V}$ & $\bar{I}$ & I & III \\
\hline
\end{tabular}

Figure 5. Comparison of water quality grades using various assessment methods. CER: comprehensive evaluation result; GCM: game theory-based cloud model; SFI: single factor index method. 
Figure 5 shows that during 2010-2014, there were 19 months (31.67\%) at grade I, 39 months $(65.00 \%)$ at grade II, and one month each at grade IV and V. Generally, most of the results between GCM and CER are in accordance with each other; in particular, a total of 52 months (86.6\%) were in exactly the same grade. Large differences were found in three months (February 2010, August 2014 and September 2014) and five months presented a small difference. Figure 5 also shows that the results of SFI were quite different from the CERs and the GCMs. Generally, the SFI results are conservative so that the water quality features poor grades.

According to Figure 5, there are eight different results between GCM and CER. Such differences exist likely because the CER results were evaluated by more than 20 indexes, while the GCM results only used nine indexes in this study; additionally, some randomness or fuzziness in some of the indicators might not have been detected among the methods of CERs. We took these eight months as an example to display the advantage of GCM. According to Table 4, the certainty degree provides more detailed information than the simple final grade by pointing out the certainty degree that belonged to a specific water quality grade. For instance, in February 2010 and August 2014 these grades were both grade V, while the certainty degree of grade V in August 2014 was 0.1397, which was above that of February 2010 (0.1209). Considering the local test and water supply conditions, the water quality in August 2014 was environmentally poorer than that in February 2010. We can see that the game theory-based cloud model approach not only indicates the water quality grade but also further indicates the severity of water quality at the same grade. In addition, from the certainty degree value in Table 4, we can see that in February 2010, the certainty degree of grade V was 0.1209 , which is only 0.0078 higher than grade I; in August 2014, the certainty degree of grade V was 0.1397, only 0.001 higher than I; in September 2014, the certainty degree of grade IV was 0.1363 , only 0.0004 higher than I. It is clear that the GCM could detect such small differences and then tend toward a worse grade. For example, both the results of GCM and SFI detected the water quality in February 2010 as grade $\mathrm{V}$ while CER detected it as grade I. We believe that the method of CER could not detect the small difference due to the randomness and fuzziness in the dataset, resulting in such a large difference. Additionally, the results of SFI were worse than the results of GCM, which was determined by the method itself. Generally, the game theory-based cloud model could not only detect a more reasonable water quality result by reducing the randomness and fuzziness using the certainty degree but also provide more detailed information on the water quality grades.

Table 4. Water quality assessed via cloud model-based assessment approach.

\begin{tabular}{cccccccc}
\hline \multirow{2}{*}{ Time } & \multicolumn{5}{c}{ Final Certainty Degrees } & \multirow{2}{*}{$\begin{array}{c}\text { Final Water } \\
\text { Quality Grade }\end{array}$} \\
\cline { 2 - 6 } & Grade I & Grade II & Grade III & Grade IV & Grade V & Grade VI & V \\
February 2010 & 0.1131 & 0.1172 & 0.0011 & 0.0068 & 0.1209 & 0.0008 & II \\
January 2011 & 0.2149 & 0.2152 & 0.0016 & 0.0304 & 0.0638 & 0.0003 & II \\
February 2012 & 0.1957 & 0.2574 & 0.0063 & 0.0000 & 0.0131 & 0.0145 & II \\
July 2012 & 0.1453 & 0.2692 & 0.0202 & 0.1079 & 0.0001 & 0.0000 & II \\
June 2013 & 0.0913 & 0.2110 & 0.0055 & 0.0248 & 0.0730 & 0.0004 & V \\
August 2014 & 0.1387 & 0.1299 & 0.0126 & 0.0019 & 0.1397 & 0.0014 & IV \\
September 2014 & 0.1359 & 0.1355 & 0.0082 & 0.1363 & 0.0031 & 0.0012 & II \\
December 2014 & 0.1591 & 0.2042 & 0.0144 & 0.0000 & 0.0001 & 0.0513 & \\
\hline
\end{tabular}

\subsection{Analysis of Weight Impacts Water Quality Grade}

To verify whether the comprehensive weight has more advantages than the single weight, we input different weights (Table 3) into the cloud model to evaluate the water quality. As shown in Table 5, the similarity between AHPW and CW was 91.7\% (55/60), and the similarity between EW and CW was $83.3 \%(50 / 60)$, while the similarity between AHPW and EW was only $76.7 \%(46 / 60)$. The high similarity between AHPW and CW mainly occurred because the weight coefficient of AHPW was set to $\alpha_{1}=0.7487$, which means the AHPW is closer to the CW. 
Table 5. Comparison of water quality grades based on game theory-based cloud model using various weights.

\begin{tabular}{|c|c|c|c|c|c|c|c|c|c|c|c|c|c|c|c|}
\hline \multirow{3}{*}{ Time Series } & \multicolumn{3}{|c|}{2010} & \multicolumn{3}{|c|}{2011} & \multicolumn{3}{|c|}{2012} & \multicolumn{3}{|c|}{2013} & \multicolumn{3}{|c|}{2014} \\
\hline & \multicolumn{3}{|c|}{ Weight Methods } & \multicolumn{3}{|c|}{ Weight Methods } & \multicolumn{3}{|c|}{ Weight Methods } & \multicolumn{3}{|c|}{ Weight Methods } & \multicolumn{3}{|c|}{ Weight Methods } \\
\hline & AHPW & EW & $\mathrm{CW}$ & AHPW & EW & CW & AHPW & EW & $\mathrm{CW}$ & AHPW & EW & $\mathrm{CW}$ & AHPW & EW & CW \\
\hline January & II & II & II & II & II & II & $\mathrm{I}$ & I & I & I & I & I & II & II & II \\
\hline February & $\mathrm{V}$ & $\mathrm{V}$ & $\mathrm{V}$ & I & I & I & II & II & II & I & II & I & II & III & II \\
\hline March & I & I & I & I & III & I & II & IV & II & I & I & I & II & II & II \\
\hline April & I & II & I & I & I & I & I & I & I & II & II & II & II & II & II \\
\hline May & II & I & I & II & II & II & II & II & II & II & II & II & II & II & II \\
\hline June & I & I & I & III & II & II & II & II & II & II & II & II & II & II & II \\
\hline July & II & III & II & II & II & II & II & II & II & II & III & II & I & I & I \\
\hline August & I & I & I & II & II & II & IV & II & II & I & I & I & V & V & V \\
\hline September & II & II & II & I & III & I & II & II & II & II & II & II & III & III & IV \\
\hline October & I & I & I & II & I & I & II & I & II & II & II & II & II & II & II \\
\hline November & II & II & II & II & II & II & II & II & II & I & I & I & I & I & I \\
\hline December & I & I & I & II & II & II & II & II & II & II & II & II & II & II & II \\
\hline
\end{tabular}

Generally, the different results mainly manifest since there were only one or two grade gaps between the results based on the three weights, suggesting that the index weight is not particularly sensitive to the cloud model. Even so, some differences still exist among the three groups of results. For example, in September 2014, the result of the CW was at grade IV, while the results of AHPW and EW were both at grade III. By analyzing the raw data of water quality monitoring, the measured values of COD and Fc were $19.8 \mathrm{mg} / \mathrm{L}$ and 9972 per liter, respectively, during this month (Figure 6), while the criteria of COD and Fc at grade III were $\leq 20 \mathrm{mg} / \mathrm{L}$ and $\leq 10,000$ per liter. The measured value was very close to the threshold values; in this case, the evaluation results of EW and AHPW were all at grade III. However, combining Figure 5 and Table 4 and considering the raw dataset of other indexes, the fuzziness of the evaluation criteria, and the randomness of the monitoring results, we see that the water quality grade would be more reasonable if it were at grade IV. As another example, the water quality grade in March 2012 was at grade IV when using the EW. According to Figure 5 and the raw values, we found that grade II would be more reasonable. Accordingly, we can see that a combination weight based on game theory specializes in overcoming these problems of one-sidedness of single weight. At the same time, the measured content of COD, TN, and FC showed an increasing trend from Figure 6. It is possible that the annual increase in the number of inhabitants of Qingyuan has led to the increasing of domestic sewage emissions, resulting in the worsening of water pollution.

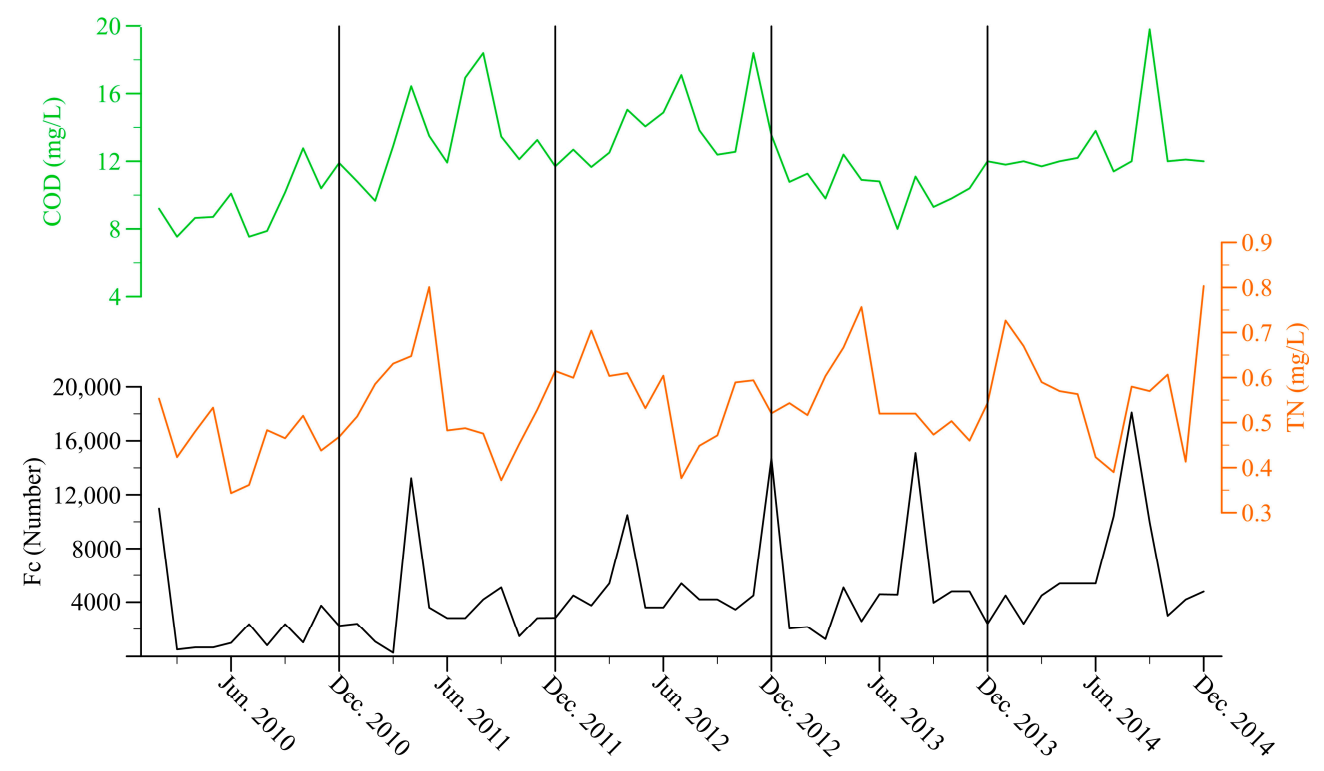

Figure 6. Actual measured values of COD, TN, and Fc. 


\subsection{Analysis of Cloud Drop Distribution}

According to the parameters $\left(E_{x}, E_{n}\right.$, and $\left.H_{e}\right)$ of the cloud model identified in Table 2, the forward cloud generators were adopted to generate the qualitative conceptual cloud model of each index, as shown in Figure 7. In summary, the clouds of different indexes at various grades could be differentiated, especially in Figure $7 a, b, e-g, i$, without much interruption or overlap. The cloud of grade II and grade III in Figure 7c,d overlapped partially, and the cloud of grade II and grade III in Figure $7 \mathrm{~h}$ overlapped completely.
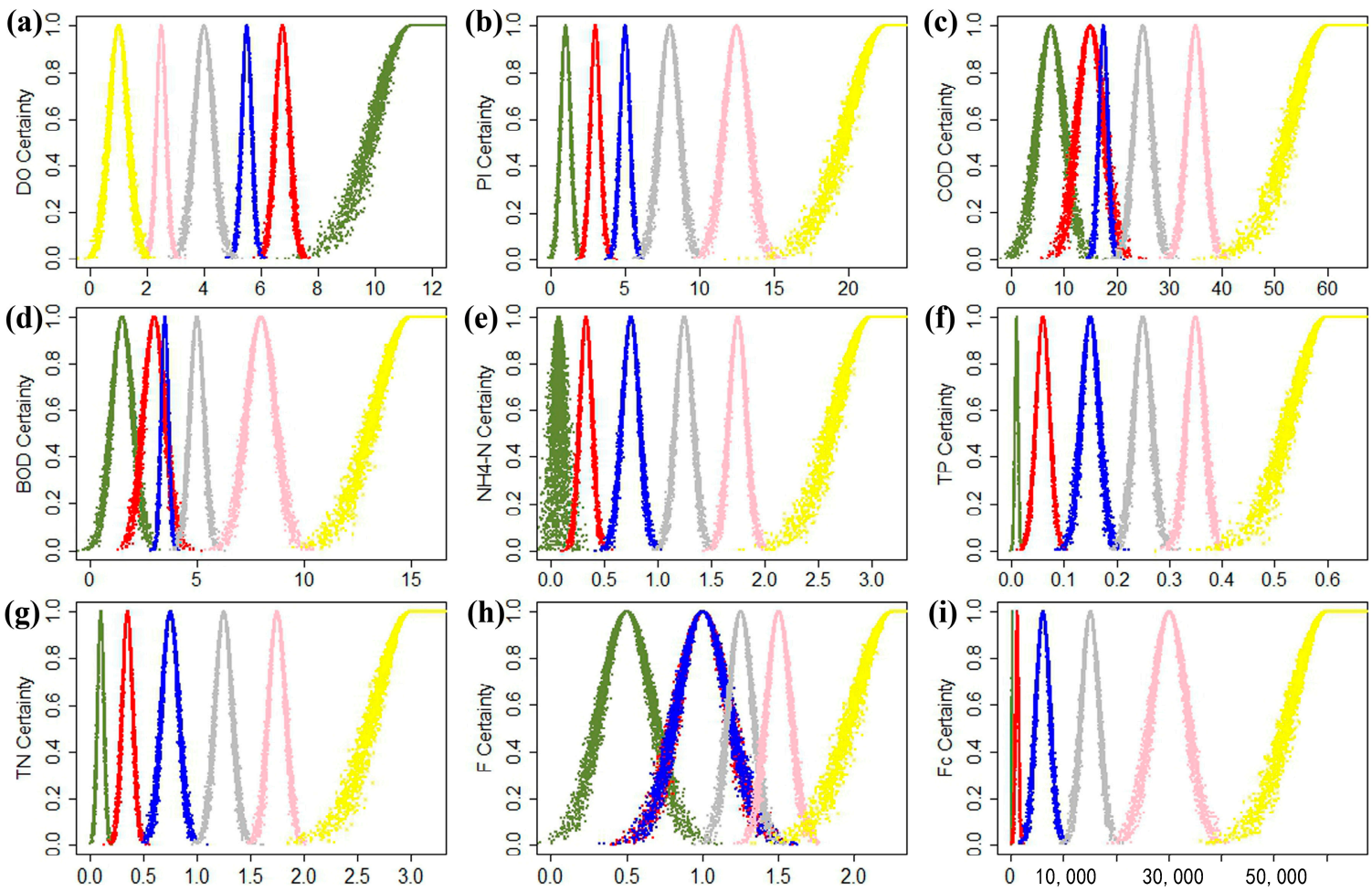

Figure 7. Forward clouds of different indexes at various water quality grades. (a) DO; (b) PI; (c) COD; (d) BOD; (e) $\mathrm{NH}_{4}{ }^{+}-\mathrm{N}$; (f) TP; (g) TN; (h) F; and (i) Fc. The dark olive-green, red, blue, gray, pink, and yellow scatter cloud represent grades I, II, III, IV, V, and VI, respectively.

The distribution of clouds is directly related to the parameters $\left(E_{x}, E_{n}\right.$, and $\left.H_{e}\right)$ which have specific physical meanings ( $E_{x}$ : the center of the cloud, $E_{n}$ : the width of the cloud, $H_{e}$ : the concentration of the cloud (or the dispersion degree of clouds)). The cloud overlap is mainly influenced by $E_{x}$. According to Table 1 , the quantitative boundaries of COD are grade I $(\leq 15)$, grade II $(\leq 15)$, and grade III $(\leq 15)$, the quantitative boundaries of BOD are grade I $(\leq 3)$, grade II $(\leq 3)$ and grade III $(\leq 4)$, respectively. Apparently, the criteria of COD and BOD in grade I and grade II were identical, thus the $E_{x}$ values of grade I and grade II calculated according to Equations (1) and (2) were very close, which is reason why the clouds in Figure 7c,d overlap, similar to Figure $7 \mathrm{~h}$.

To further explore the overlap problem in Figure $7 \mathrm{c}, \mathrm{d}, \mathrm{h}$, we modified the quantitative boundaries of COD, BOD, and F. After repeated trial, we discovered that when the modified quantitative boundaries of COD were set to grade I $(\leq 10)$, the BOD set to grade $\mathrm{I}(\leq 1.5)$, and the F set to grade I $(\leq 0.2)$ and Grade II $(\leq 0.5)$, the overlap problems can be greatly improved (Figure 8$)$. We integrated the modified parameters into the original model for further evaluation and found that approximately $90 \%$ (54/60) of the grades were identical to the CER, which improved the results by $3.4 \%$ compared to the original results. The above analysis shows that the results of accuracy can be improved by modifying the quantitative boundaries, which may provide a reference for accuracy improvement. 

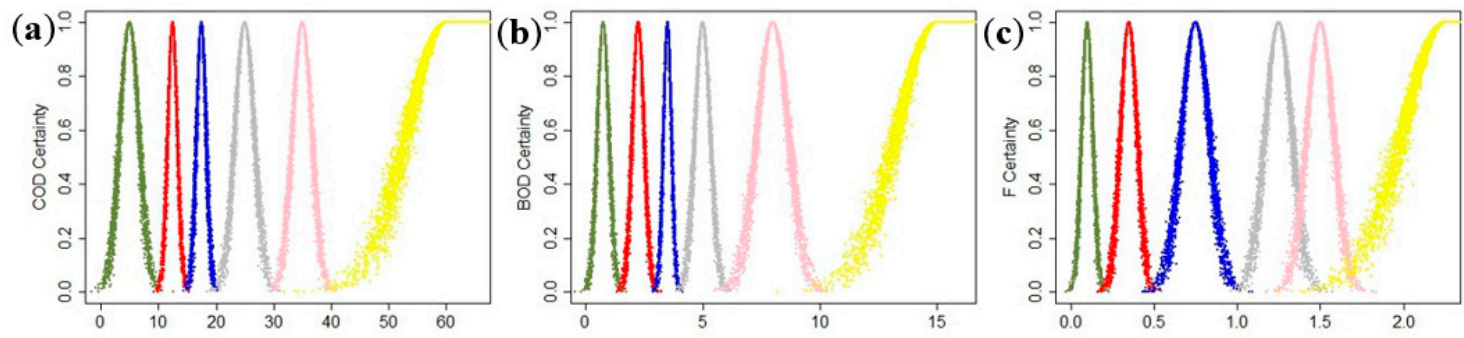

Figure 8. The modified forward cloud corresponding to different water quality grades of (a) COD; (b) BOD; and (c) F.

\section{Summary and Conclusions}

In this study, we first combined the subjective weight (AHPW) and the objective weight (EW) via game theory to calculate a combination weight; then, we constructed an evaluation system of the cloud model based on the combination weight; finally, we applied this theory-based cloud model to evaluate the water quality in the Qixinggang section of the Beijiang River. The results show that the CW ranks Fc as the most important indexes, followed by TN and TP, while BOD and F were considered the least important indexes. The $\mathrm{CW}$ presents significant advantages to improve the deficiencies of both subjective and objective weights. During 2010-2014, there were 19 months (31.67\%) at grade I, 39 months $(65.00 \%)$ at grade II, and one month each at grade IV and grade V. A total of 52 months $(86.6 \%)$ of GCM were identical to those of the CER, which implies the rationality of the proposed model in this study. The water quality grades of GCM were close to the grades of AHPW due to the weight coefficient of AHPW being set to 0.7487 . There were generally one or two grade gaps among the results of the three weights, suggesting that the index weight is not particularly sensitive to the cloud model. The evaluated accuracy of water quality can be improved by modifying the quantitative boundaries. Generally, the results of this study could provide a reference for water quality evaluation, prevention, and improvement of water quality assessment and other applications.

Acknowledgments: The research is financially supported by the National Key R\&D Program of China (2017YFC0405900), National Natural Science Foundation of China (Grant No. 91547202, 51709117, 51210013, 51479216), and China Postdoctoral Science Foundation (2017M612662).

Author Contributions: B.Y. and X.C. conceived and designed the research. B.Y. performed data analysis, and wrote the manuscript. Extensive editing and revisions to the final manuscript and conclusions were contributed by C.L., B.Y. and X.C., X.W. was responsible for collecting and preliminarily analyzing the data. Y.H. proposed some constructive suggestions about the research. All authors read and approved the manuscript.

Conflicts of Interest: The authors declare no conflict of interest.

\section{References}

1. Yao, M.; Tramberend, S.; Kabat, P.; Hutjes, R.W.A.; Werners, S.E. Building Regional Water-Use Scenarios Consistent with Global Shared Socioeconomic Pathways. Environ. Process. 2017, 4, 15-31. [CrossRef]

2. Cook, H.F. The Protection and Conservation of Water Resources; John Wiley \& Sons: Hoboken, NJ, USA, 2017.

3. Wang, Z.L.; Xie, P.W.; Lai, C.G.; Chen, X.H.; Zeng, Z.Y.; Li, J. Spatiotemporal variability of reference evapotranspiration and contributing climatic factors in China during 1961-2013. J. Hydrol. 2017, 544, 97-108. [CrossRef]

4. Jackson, A.R.W.; Jackson, J.M. Environmental Science: The Natural Environment and Human Impact; Pearson Education: London, UK, 2000.

5. Goudie, A.S. The Human Impact on the Natural Environment: Past, Present, and Future; John Wiley \& Sons: Hoboken, NJ, USA, 2013.

6. Peters, N.E.; Meybeck, M. Water quality degradation effects on freshwater availability: Impacts of human activities. Water Int. 2000, 25, 185-193. [CrossRef] 
7. Chea, R.; Grenouillet, G.; Lek, S. Evidence of water quality degradation in lower Mekong basin revealed by self-organizing map. PLoS ONE 2016, 11, e0145527. [CrossRef] [PubMed]

8. Kozaki, D.; Harun, N.; Rahim, M.; Mori, M.; Nakatani, N.; Tanaka, K. Determination of Water Quality Degradation Due to Industrial and Household Wastewater in the Galing River in Kuantan, Malaysia Using Ion Chromatograph and Water Quality Data. Environments 2017, 4, 35. [CrossRef]

9. Wang, D.; Singh, V.P.; Zhu, Y.S. Hybrid fuzzy and optimal modeling for water quality evaluation. Water Resour. Res. 2007, 43, W05415. [CrossRef]

10. Qian, Y.; Migliaccio, K.W.; Wan, Y.S.; Li, Y.C. Surface water quality evaluation using multivariate methods and a new water quality index in the Indian River Lagoon, Florida. Water Resour. Res. 2007, 43, W08405. [CrossRef]

11. Primpas, I.; Tsirtsis, G.; Karydis, M.; Kokkoris, G.D. Principal component analysis: Development of a multivariate index for assessing eutrophication according to the European water framework directive. Ecol. Indic. 2010, 10, 178-183. [CrossRef]

12. Moya, C.E.; Raiber, M.; Taulis, M.; Cox, M.E. Hydrochemical evolution and groundwater flow processes in the Galilee and Eromanga basins, Great Artesian Basin, Australia: A multivariate statistical approach. Sci. Total Environ. 2015, 508, 411-426. [CrossRef] [PubMed]

13. Dahiya, S.; Singh, B.; Gaur, S.; Garg, V.K.; Kushwaha, H.S. Analysis of groundwater quality using fuzzy synthetic evaluation. J. Hazard. Mater. 2007, 147, 938-946. [CrossRef] [PubMed]

14. Kotti, I.P.; Sylaios, G.K.; Tsihrintzis, V.A. Fuzzy logic models for BOD removal prediction in free-water surface constructed wetlands. Ecol. Eng. 2013, 51, 66-74. [CrossRef]

15. Aguilera, P.A.; Frenich, A.G.; Torres, J.A.; Castro, H.; Vidal, J.L.M.; Canton, M. Application of the kohonen neural network in coastal water management: Methodological development for the assessment and prediction of water quality. Water Res. 2001, 35, 4053-4062. [CrossRef]

16. Kuo, J.T.; Wang, Y.Y.; Lung, W.S. A hybrid neural-genetic algorithm for reservoir water quality management. Water Res. 2006, 40, 1367-1376. [CrossRef] [PubMed]

17. Ay, M.; Kisi, O. Modelling of chemical oxygen demand by using ANNs, ANFIS and k-means clustering technique. J. Hydrol. 2014, 511, 279-289. [CrossRef]

18. Li, D.Y.; Liu, C.Y.; Gan, W.Y. A new cognitive model: Cloud model. Int. J. Intell. Syst. 2009, 24, 357-375. [CrossRef]

19. Wang, J.Q.; Lu, P.; Zhang, H.Y.; Chen, X.H. Method of multi-criteria group decision-making based on cloud aggregation operators with linguistic information. Inf. Sci. 2014, 274, 177-191. [CrossRef]

20. Tiwari, A.K.; Singh, A.K.; Singh, A.K.; Singh, M.P. Hydrogeochemical analysis and evaluation of surface water quality of Pratapgarh district, Uttar Pradesh, India. Appl. Water Sci. 2017, 7, 1609-1623. [CrossRef]

21. Mohseni-bandpey, A.; Majlessi, M.; Kazempour, A. Evaluation of Golgol river water quality in Ilam province based on the National Sanitation Foundation Water Quality Index (NSFWQI). J. Health Field. 2017, 1, 7-16.

22. Zou, Q.; Zhou, J.Z.; Zhou, C.; Song, L.X.; Guo, J. Comprehensive flood risk assessment based on set pair analysis variable fuzzy sets model and fuzzy AHP. Stoch. Environ. Res. Risk Assess. 2013, 27, 525-546. [CrossRef]

23. Jin, F.F.; Pei, L.D.; Chen, H.Y.; Zhou, L.G. Interval-valued intuitionistic fuzzy continuous weighted entropy and its application to multi-criteria fuzzy group decision making. Knowl.-Based Syst. 2014, 59, 132-141. [CrossRef]

24. Roger, B.M. Game Theory: Analysis of Conflict; Harvard University Press: Cambridge, UK, 1991.

25. Wu, T.-Y.; Lee, W.-T.; Guizani, N.; Wang, T.-M. Incentive mechanism for P2P file sharing based on social network and game theory. J. Netw. Comput. Appl. 2014, 41, 47-55. [CrossRef]

26. Aumann, R.J. Game Theory; Palgrave Macmillan: Basingstoke, UK, 1989; pp. 1-53.

27. Hjaila, K.; Puigjaner, L.; Laínez, J.M.; Espuna, A. Integrated game-theory modelling for multi enterprise-wide coordination and collaboration under uncertain competitive environment. Comput. Chem. Eng. 2017, 98, 209-235. [CrossRef]

28. Lahlou, S.; Wynter, L. A Nash equilibrium formulation of a tradable credits scheme for incentivizing transport choices: From next-generation public transport mode choice to HOT lanes. Transp. Res. B-Meth. 2017, 101, 185-212. [CrossRef]

29. Wang, Z.L.; Zhong, R.D.; Lai, C.G.; Zeng, Z.Y.; Lian, Y.Q.; Bai, X.Y. Climate change enhances the severity and variability of drought in the Pearl River Basin in South China in the 21st century. Agric. For. Meteorol. 2018, 249, 149-162. [CrossRef] 
30. Altman, E.I. Predicting Financial Distress of Companies: Revisiting the Z-Score and ZETA Models; Stern School of Business, New York University: New York, NY, USA, 2000; pp. 9-12.

31. Li, D.Y.; Liu, C.Y.; Liu, L.Y. Study on the universality of the normal cloud model. Eng. Sci. 2004, 6, $28-34$.

32. Du, X.Y.; Yi, Q.J.; Huang, K.D.; Liang, D.N. Transformation between qualitative variables and quantity based on cloud models and its application (in Chinese with English abstract). Syst. Eng. Electron. 2008, 30, 772-776.

33. Liu, D.F.; Wang, D.; Wu, J.C.; Wang, Y.K.; Wang, L.C.; Zou, X.Q.; Chen, Y.F.; Chen, X. A risk assessment method based on RBF artificial neural network-cloud model for urban water hazard. J. Intell. Fuzzy Syst. 2014, 27, 2409-2416.

34. Ministry of Ecology and environment of the People's Republic of China. Surface Water Environmental Quality Standard; GB3838-2002; Ministry of Ecology and Environment of the People's Republic of China: Beijing, China, 2002.

35. Lai, C.G.; Chen, X.H.; Chen, X.Y.; Wang, Z.L.; Wu, X.S.; Zhao, S.W. A fuzzy comprehensive evaluation model for flood risk based on the combination weight of game theory. Nat. Hazards 2015, 77, 1243-1259. [CrossRef]

36. Saaty, T.L. How to make a decision: The analytic hierarchy process. Eur. J. Oper. Res. 1990, 48, 9-26. [CrossRef]

37. Garg, N.; Sadiq, M.; Agarwal, P. Goal Oriented Approach for Software Requirements Elicitation and Prioritization Using Analytic Hierarchy Process. In Proceedings of the 5th International Conference on Frontiers in Intelligent Computing: Theory and Applications; Springer: Singapore, 2017; pp. 281-287.

38. Agapova, M.; Bresnahan, B.W.; Linnau, K.F.; Garrison, L.P.; Higashi, M.; Kessler, L.; Devine, B. Using the analytic hierarchy process for prioritizing imaging tests in diagnosis of suspected appendicitis. Acad. Radiol. 2017, 24, 530-537. [CrossRef] [PubMed]

39. Trivedi, A.; Singh, A. A hybrid multi-objective decision model for emergency shelter location-relocation projects using fuzzy analytic hierarchy process and goal programming approach. Int. J. Proj. Manag. 2017, 35, 827-840. [CrossRef]

40. Stefanidis, S.; Stathis, D. Assessment of flood hazard based on natural and anthropogenic factors using analytic hierarchy process (AHP). Nat. Hazards 2013, 68, 569-585. [CrossRef]

41. Xie, L.; Li, G.Y.; Peng, L.; Chen, Q.C.; Tan, Y.L.; Xiao, M. Band selection algorithm based on information entropy for hyperspectral image classification. J. Appl. Remote Sens. 2017, 11, 026018. [CrossRef]

42. Xu, C.; Hu, C.K.; Liu, X.L.; Wang, S.J. Information Entropy in Predicting Location of Observation Points for Long Tunnel. Entropy 2017, 19, 332. [CrossRef]

43. Yan, J.H.; Feng, C.H.; Li, L. Sustainability assessment of machining process based on extension theory and entropy weight approach. Int. J. Adv. Manuf. Technol. 2014, 71, 1419-1431. [CrossRef]

44. Khan, J.F.; Bhuiyan, S.M. Weighted entropy for segmentation evaluation. Opt. Laser Technol. 2014, 57, $236-242$. [CrossRef]

45. Prati, L.; Pavanello, R.; Pesarin, F. Assessment of surface water quality by a single index of pollution. Water Res. 1971, 5, 741-751. [CrossRef]

(C) 2018 by the authors. Licensee MDPI, Basel, Switzerland. This article is an open access article distributed under the terms and conditions of the Creative Commons Attribution (CC BY) license (http:/ / creativecommons.org/licenses/by/4.0/). 